\title{
SARS-CoV-2 Evolves Through Constitutive Adjustments or Else Via Executive, Medical and Social Struggle
}

Daniel Benharroch, M.D ${ }^{1 *}$, Yane-Bianca Benharroch ${ }^{2}$

${ }^{1}$ Professor, Department of Pathology, Soroka University Medical Center, and Faculty of Health Sciences, Ben Gurion University of the Negev, BeerSheva, Israel

${ }^{2}$ Kibbutz Sde-Boker, Israel

DOI: $10.36347 /$ sjams.2020.v08i05.039

| Received: 14.05.2020 | Accepted: 21.05.2020 | Published: 30.05 .2020

*Corresponding author: Daniel Benharroch

Abstract

Original Research Article

In a recent article, we have divided the cases of COVID-19 occurring in several nations into three groups, A to C, based on the rate of severe-critical patients out of the total number of infected patients, the ratio of deaths and the proportion of recovering individuals, together with various percentages thereof. Five nations were found to agree with our classification to group A, and they were evaluated for a stepwise progress during a period of 30-36 days. This was performed, in an effort to appraise the relative significance of the unbiased correlation between the SARS-CoV-2, the specific environment and the population set up, as it contrasts with the medical, social and executive struggle to overcome the disease. The comparison was done, in the absence of an efficient, specific treatment or of an effective vaccine. The death rate/1 million-population was assessed in the context of the above analogy.

Keywords: COVID-19 group A; transit; transformation; death per 1 million-population; follow-up; PCR novel coronavirus tests.

Copyright @ 2020: This is an open-access article distributed under the terms of the Creative Commons Attribution license which permits unrestricted use, distribution, and reproduction in any medium for non-commercial use (NonCommercial, or CC-BY-NC) provided the original author and source are credited.

\section{INTRODUCTION}

The three groups of states, described previously, differ by a disparate combination of the three variables, in number and in percentage of the total number of COVID-19 patients [1, 2]. Thus, group A presents with low levels of the three variables: a low grade (and percentage) of critical patients; a low mortality, but also a low recovery rank $[3,4]$. Patients, who do not recover, will remain in a carrier state, the crux of which is not completely clarified. Group A will be the core of our discussion $[1,2,5]$.

In contrast, group B patients are very ill and often die of the complications of COVID-19. But, of those who survive, a large proportion finally heals. Group $\mathrm{C}$ is conceived as an intermediary entity. Grossly, it is much reminiscent of group A, except that these patients eventually recover [1].

Presently, our plan is to follow group A states, from description in late March, 2020 to the beginning of May, 2020. One country, the UK, was excluded due to missing of some of its significant data.

The aim of this opinionated paper is to attempt to display the most appropriate of two possible attitudes. In the near-total absence of effective therapy directed at the novel coronavirus, and with a lack of vaccine, which opportunity should one choose? Given priority to the medical, social and executive forms of struggle, force might be used with quasi-illegal, coercive methods to implement the rules deemed compulsory, on the one hand. On the other hand, following the evolution of SARS-CoV-2, one may try to demonstrate that, in group A, a constitutive setup of the class of humans and the milieu they live in, may be disclosed to contain the pandemic. This program evokes those conceived to lead a nation achieve herd immunity (the UK at the start of the COVID-19, and for a short trial, or Sweden, for two months or more). Otherwise transformation into another group of countries COVID19 might alter the disease characteristics, but could that step be of a defensive nature?!! [1,2].

\section{Methods}

Data

were

collected

from

Worldometer.coronavirus at several points in time. Five countries were concerned as belonging, at least provisionally to group A: the USA, Germany, Turkey, Norway and Israel. For each state, the following data were gathered: the total number of the diseased; the number and rate of critical patients; the death ratio and 
the healing number and proportion. This collection was repeated several times during a month or so. We made a note, in addition, of the number of PCR tests performed per country and calculated twice the death rate per 1 million-population for each state. The discussion will attempt to expose the comparison between the natural evolution of the COVID-19 and the man-made intrusion into the development of this infectious disease [3, 4].

\section{RESULTS}

A transformation of the classification to a new country-group occurred once in four of the five nations under observation; they transited into group $\mathrm{C}$ countries, with patients, healing in a majority of the cases. The last, Norway, persisted in group A status, for the whole duration of the study.

Table-1 describes the distribution of death/1 million-population for the five states which had previously belonged, at least temporarily to group A. It depicts also the mortality, as it relates to the total numbers of infected patients. To the same token, one may observe in this Table, that, at the top of the list, in an increasing order of the death rate, are two nations of tiny size and/or tiny population. The first, Israel, displayed 0.0001 death/1 million-inhabitants, and as much as 21,634 PCR tests were performed, while Norway was next, with 0.0032 deaths/per millionpopulation and 33,624 tests of PCR. Both states displayed a low recovery ratio, however.

Germany, Turkey and the USA followed suit, in the same increasing order of death rate. The death/1 million-inhabitants raised from 0.0094 for Germany; 0.0167 , for Turkey and culminated at 0.130 with the USA. The total number of tests/1M was highest for Germany, lowest for Turkey and moderate-to-low for the US, while they belonged to the status of group A countries. Transformation from group A to group C

As mentioned above, Norway is the only state of the five, to have remained in group A and this lasted for 38 days. The number of contaminated patients here climaxed at 7,884, with few severe-to-critical patients and an even lower recovery rate. The PCR tests performed reached 33,624. Death/1M inhabitants progressed to 0.0214 in the absence of conversion to a different country group.
Like the remainder of the subset, Israel did transform to group $\mathrm{C}$, two weeks after description. The polluted population had reached 16,237 , the number of critically affected people had dropped markedly, the death ratio was limited to $1.44 \%$, but healing concerned $9,858(59 \%)$ individuals. The conversion herewith, was a late one, and the progression to recovery carried much promise. The death/1M-population climbed to 0.0234 in this country, during transformation.

In contrast to Israel, Germany transformed its group classification within 5 days from inception. Here, we describe 165,786 infected human beings, $1.18 \%$ of whom were in critical condition and 6893 (4.16\%) died of the sequels of the COVID-19. The bright side was the healing of $132,700(80 \%)$ in this country. These findings highlight a definite step towards cure, if not an overthrow of the epidemic. However, this outcome is not conceivable before specific therapy and the acquisition of an appropriate vaccine are established. The mortality/1M-inhabitants in Germany stepped up briskly to 0.6888 .

Turkey proceeded also to group $\mathrm{C}$, and that after 34 days from the start. This change of classification was made possible by a low rate of a very severe illness, $1384(1.08 \%)$, mortality of $2.7 \%$, but that with an excess of healing $(53.4 \%)$. The most striking change in the transition from an A group to a $\mathrm{C}$ group, should consistently include the multiplication of the rate of recovery. This may allow a cure proportionate to the degree of healing. The mortality rate/1M-population progressed to 0.3459 .

The USA remained in group A for nearly three weeks. Meanwhile, the number of diseased patients augmented markedly, and constantly. When recovery concerned 48,708 (7.55\%) individuals, this was the indication for the change to group C. However, by the ensuing week, the number of patients had doubled. In addition, both the mortality and the healing rate had stepped up, indicating probably, an atypical transformation into group B, suggesting a deteriorating situation, perhaps with the prospect of a poor outcome. The mortality ratio/1M-inhabitants increased many folds, to 6.9127 .

Table-1: Distribution by increasing order of death per one million-population in countries classified temporarily as belonging to group $\mathrm{A}$

\begin{tabular}{|l|l|l|l|l|l|}
\hline & Israel n (\%) & Norway n (\%) & Germany n (\%) & Turkey n (\%) & USA n (\%) \\
\hline Population & $9,136,000$ & $5,367,580$ & $83,186,719$ & $83,154,997$ & $328,239,523$ \\
\hline Mortality & $1(0.09)$ & $32(0.72)$ & $(0.38) 94$ & $168(1.55)$ & $1301(1.52)$ \\
\hline Recovery & $37(3.47)$ & $(0.27) 12$ & $(1.07) 266$ & $162(1.49)$ & $1868(2.18)$ \\
\hline Serious pt. & $(1.68) \quad 18$ & $(2.17) 97$ & $(0.092) 29$ & $(5.25) 568$ & $2122(2.48)$ \\
\hline Death/1M & 0.0001 & 0.0032 & 0.0094 & 0.01679 & 0.130 \\
\hline Tests/1M & 21,634 & 33,624 & 30,400 & 13,886 & 22,282 \\
\hline
\end{tabular}


Table-2: Distribution of previous group A countries, following their transformation predominantly into group C countries

\begin{tabular}{|c|c|c|c|c|c|}
\hline & Israel n (\%) & Norway n (\%) & Germany n (\%) & Turkey n (\%) & USA n (\%) \\
\hline Population & $9,136,000$ & $5,367,580$ & $83,186,719$ & $83,154,997$ & $328,239,523$ \\
\hline Mortality & $234(1.44)$ & $214(2.71)$ & $6893(4.16)$ & $3461(2.7)$ & $69,142(5.8)$ \\
\hline Recovery & (59)9858 & $32(0.4)$ & $132,700(80)$ & $\begin{array}{ll}(53.4) & 66,166 \\
\end{array}$ & $181,603(15.12)$ \\
\hline Critical pts. & $93(0.57)$ & $27(0.34)$ & $1949(1.18)$ & $(1.08)$ & $16,039(1.34)$ \\
\hline Death/1M & 0.0234 & 0.0214 & 0.6888 & 0.3459 & 6.9127 \\
\hline
\end{tabular}

\section{DISCUSSION}

Our focus was centered on five states, which were defined at some point in the pandemic, as group A countries. Four of these underwent a further reclassification, mainly into group $\mathrm{C}$ nations. Common to both categories are a relatively low count of patients in severe-critical conditions, in addition to a low mortality ratio. However the recovery is highly contrasted, being low for group A countries, and much higher for group $\mathrm{C}$ countries. The marker, death rate/1M-inhabitants was steeper, after transformation into group $\mathrm{C}$.

Among the states investigated, one, Norway, kept its classification as a group A country, at all times, for 38 days, but its features progressed slightly, towards a more aggressive disease. The second exception, that of the USA was more atypical. They had remained a group A nation for more than three weeks. By that time the disease became progressively more aggressive. Then it transited shortly through a group $\mathrm{C}$ phase, to finally reach the status of a group B disease. The most consistent marker of the illness progression is probably the death ratio/1M-inhabitants, which evolved from 0.130 at the first stage, to 6.9127 towards the end of the follow-up.

Upon the redaction of this paper, no vaccination was yet available. Treatment with three antivirals is just being initiated. Thus, this era should be assumed as a pretreatment one [4].

Transformation from one group of country to the next is considered a natural event, related probably with a novel exposure of the novel coronavirus to a different environment, as well as to humans of different constitution. A mutation should not be excluded as well. The only marking change which occurred with the above transformation, was evidence of more aggressive symptoms and most specifically a rise in the mortality (/1M-population).
We conclude that, in the absence (at this time!) of a specific therapy and vaccines, whatever the governments, Medicine and the social institutions attempted, including hygiene, social distancing, facial masks, preventing large gathering and the widespread use of the confinement; these, together with treatment of complication of COVID-19, were effective [4].

All of these man-made contributions, which in the absence of a natural development, including the failure of the few attempts at obtaining herd immunity, as well as the absent benefit at the transformation of the classifications of the group-country, represent whatever could be done at this stage $[4,5]$.

Acknowledgements: Thanks to Assaf Benharroch for a constructive debate.

The authors declare 'no conflict of interest exists'.

No funding was requested.

\section{REFERENCES}

1. Benharroch D, Benharroch YB, Goshen I. Recovery from COVID-19 and evolution, 03.22.2020. J Human Virol Retrovirol. 2020;8:110-13.

2. Goshen I, Benharroch A, Benharroch D. Tribulations of the SARS-CoV-2 over the globe. Sch J Applied Med Sci. 2020;8:1170-1173.

3. Guo YR, Cao QD, Hong ZS, Tan YY, Chen SD, Jin HJ, Tan KS, Wang DY, Yan Y. The origin, transmission and clinical therapies on coronavirus disease 2019 (COVID-19) outbreak-an update on the status. Military Medical Research. 2020 Dec;7(1):1-10

4. Yuen KS, Ye ZW, Fung SY, Chan CP, Jin DY. SARS-CoV-2 and COVID-19: The most important research questions. Cell \& bioscience. 2020 Dec;10(1):1-5.

5. Bai Y, Lingshen Y, Tao W. Letter: presumed asymptomatic transmission of COVID-19. JAMA. 2020;323:1406-1407. 